\title{
The interplay of parental monitoring and socioeconomic status in predicting minor delinquency between and within adolescents
}

\author{
Roderik Rekker $^{\text {a, b, *, } 1}$, Loes Keijsers ${ }^{\text {d, } 2}$, Susan Branje ${ }^{\text {a, } 3}$, Hans Koot ${ }^{\text {c, } 4}$, \\ Wim Meeus ${ }^{\text {a, }}$, 3 \\ a Utrecht University, The Netherlands \\ ${ }^{\mathrm{b}}$ University of Amsterdam, The Netherlands \\ ${ }^{c}$ VU University, Department of Clinical Developmental Psychology and EMGO Institute of Health and Care Research, Amsterdam, The \\ Netherlands \\ ${ }^{\mathrm{d}}$ Tilburg University, The Netherlands
}

\section{A R T I C L E I N F O}

\section{Article history:}

Received 21 June 2016

Received in revised form 7 June 2017

Accepted 8 June 2017

Available online 30 June 2017

\section{Keywords:}

Adolescent delinquency

Parental monitoring

Socioeconomic status

Neighborhoods

Within-individual

\begin{abstract}
A B S T R A C T
This six-wave multi-informant longitudinal study on Dutch adolescents $(N=824$; age 12 -18) examined the interplay of socioeconomic status with parental monitoring in predicting minor delinquency. Fixed-effects negative binomial regression analyses revealed that this interplay is different within adolescents across time than between adolescents. Between individuals, parental solicitation and control were not significantly associated with delinquency after controlling for SES: Adolescents whose parents exercised more monitoring did not offend less than others. Within individuals, higher levels of parental control were unexpectedly associated with more delinquency, but this relation was dependent on SES: Low-SES adolescents, but not high-SES adolescents, offended more during periods in which their parents exercised more control than during other periods with less control. In contrast to earlier work, this finding suggests that monitoring could be least effective when needed most. Low-SES parents might not use monitoring effectively and become overcontrolling when their child goes astray.
\end{abstract}

(C) 2017 The Foundation for Professionals in Services for Adolescents. Published by Elsevier Ltd. All rights reserved.

Parents commonly aim to prevent their adolescent offspring from engaging in risky activities. To this end, they can monitor adolescents' activities and whereabouts (Dishion \& McMahon, 1998). For example, parents can ask questions and encourage their children to disclose information (Stattin \& Kerr, 2000), which is known as parental solicitation. Parents can also demand to be informed by setting monitoring rules, which is known as parental control. Following up on research suggesting that

\footnotetext{
* Corresponding author. University of Amsterdam, Department of Political Science, P.O. Box 15.578, 1001 NB, Amsterdam, The Netherlands. E-mail addresses: r.rekker@uva.nl (R. Rekker), loes.keijsers@uvt.nl (L. Keijsers), s.branje@uu.nl (S. Branje), j.m.koot@vu.nl (H. Koot), w.meeus@uu.nl (W. Meeus).

1 Department of Political Science, University of Amsterdam, P.O. Box 15.678, 1001 NB, Amsterdam, The Netherlands.

2 Department of Developmental Psychology, Tilburg University, P.O. Box 90.153, 5000 LE, Tilburg, The Netherlands.

3 Department of Youth \& Family, Utrecht University, P.O. Box 80.140, 3508 TC, Utrecht, The Netherlands.

4 Department of Development of Clinical Developmental Psychology, VU University, De Boelelaan 1105, 1081 HV, Amsterdam, The Netherlands.
} 
monitoring may not be as effective as previously assumed (Racz \& McMahon, 2011; Smetana, 2008; Stattin \& Kerr, 2000), some more recent studies examined for whom monitoring is effective and under what circumstances. This literature indicates that whereas monitoring may be most effective when adolescents are exposed to risk factors for problem behavior, it may be ineffective or even counter effective in the absence of risk factors (e.g., Kiesner, Poulin, \& Dishion, 2010; Laird, Marrero, \& Sentse, 2010). This longitudinal study on Dutch adolescents (age 12-18) therefore examined the interplay of parental monitoring with arguably the most classic risk factor for problem behavior: a low socioeconomic status (Merton, 1968). Specifically, we investigated whether the association of minor delinquency with parental solicitation and control would be more beneficial for low-SES adolescents. Additionally, we examined whether this hypothesized moderation is specific for parents' monitoring efforts, or whether it also applies to adolescent disclosure of information (Stattin \& Kerr, 2000).

In terms of design, this study expanded upon existing research by investigating all associations both between adolescents and within adolescents. A between-individual association means that adolescents who are monitored more, commit less offenses compared to other adolescents who are monitored less. Contrarily, a within-individual association implies that the same adolescents reveal less problem behavior during periods with more monitoring than during periods with less monitoring. Unraveling how changes in monitoring co-occur with concurrent fluctuations in delinquency may provide more relevant information for parents and practitioners, compared to studying differences between individuals (Molenaar \& Campbell, 2009; Voelkle, Brose, Schmiedek, \& Lindenberger, 2014).

\section{Parental monitoring and adolescent delinquency}

As adolescents enter middle school, they start to spend relatively more time with friends and less with their family (Larson \& Richards, 1991). Consequently, parents have fewer opportunities to supervise their activities (Dishion \& McMahon, 1998). Among peers, many adolescents experiment with risky behaviors, such as minor delinquency and substance use (Moffitt, 1993). Parents thus have to meet the challenge to protect their children from risky behavior, while at the same time promoting their autonomy. One strategy to accomplish this balance is to monitor adolescents' activities.

The effectiveness of monitoring has been a topic of scientific debate. There are theoretical reasons to believe that monitoring may be effective in preventing problem behavior, but it can also be reasoned that it may be ineffective or even counter effective. Monitoring could be effective because it may enable parents to stay involved, without being physically present (Dishion \& McMahon, 1998). To the extent that adolescents accept this involvement, it may prevent them from engaging in risky activities. Contrarily, monitoring may be ineffective because adolescents may perceive it as a form of overprotection or privacy invasion (Hawk, Hale, Raaijmakers, \& Meeus, 2008; Kakihara \& Tilton-Weaver, 2009). Adolescents typically develop a growing desire for autonomy (Noom, Deković, \& Meeus, 2001) and may therefore perceive their parents' monitoring efforts as a threat to their independence. In this case, monitoring may even become counter effective (Kerr \& Stattin, 2000) since it may be precisely this desire for autonomy that motivates many adolescents to experiment with delinquency (Agnew, 1984). Theoretically, such harmful effects of monitoring may therefore be expected particularly for more controlling monitoring strategies (Grolnick \& Pomerantz, 2009; Soenens \& Vansteenkiste, 2010). Consequently, parental control may have a stronger potential for harmful effects than parental solicitation.

Empirical evidence on the effectiveness of monitoring is mixed and varies between different monitoring strategies and research designs. Between-individual studies suggested that parental monitoring is indirectly linked to less problem behavior via more disclosure by adolescents (Fletcher, Steinberg, \& Williams-Wheeler, 2004; Klevens \& Hall, 2014; Soenens, Vansteenkiste, Luyckx, \& Goossens, 2006; Vieno, Nation, Pastore, \& Santinello, 2009; Willoughby \& Hamza, 2011). This suggests that parents' efforts to obtain information from children could preclude delinquency at least partly because children indeed disclose information in response. Consequently, studies that examined solicitation while controlling for disclosure typically revealed null results (Keijsers, Branje, VanderValk, \& Meeus, 2010; Tilton-Weaver, Burk, Kerr, \& Stattin, 2013) or even found that solicitation was related to more problem behavior (Rekker et al., 2015; Kerr, Stattin, \& Burk, 2010; Kiesner, Dishion, Poulin, \& Pastore, 2009; Stattin \& Kerr, 2000; Willoughby \& Hamza, 2011). Contrarily, parental control was still found to be associated with less problem behavior after controlling for disclosure in some studies (Stattin \& Kerr, 2000; Tilton-Weaver et al., 2013; Willoughby \& Hamza, 2011), but not in other studies (Keijsers et al., 2010; Kerr et al., 2010; Kiesner et al., 2009).

In sum, although these between-individual studies suggest that monitoring is related to less problem behavior, this effect often disappeared or reversed after controlling for disclosure. By including disclosure as a control variable, many studies have essentially examined the effect of monitoring that is not accompanied by adolescent disclosure. These studies' adverse effects suggest that a situation in which parents ask more, but adolescents do not tell more, may indicate involvement in problem behavior. Potentially, parents ask more questions in these situations (e.g., solicitation) precisely because they suspect that their child may be withholding information about risky activities (e.g., lack of disclosure). If disclosure indeed mediates the beneficial effects of monitoring (e.g., Soenens et al., 2006), mainly harmful effects (e.g., due to privacy invasion) may be visible after controlling for disclosure. Therefore, we examined monitoring effects before controlling for disclosure in this study. In sum, our first hypothesis (H1) was that adolescents whose parents exercise more solicitation and control engage in less delinquent behavior than other adolescents who are monitored less (i.e., between-individual effect).

Despite this abundance of between-individual studies, little evidence is available on within-individual associations between parental monitoring and delinquency. While other aspects of parent-child relationships (e.g., parental knowledge and involvement) were found to be associated with delinquency within adolescents across time (e.g, Farrington, Loeber, Yin, \& Anderson, 2002; Lam, McHale, \& Crouter, 2014; Rekker et al., 2015), most studies that focused on monitoring have 
predominantly investigated between-individual variation (e.g., cross-sectional studies or cross-lagged models; Hamaker, Kuiper, \& Grasman, 2015). If monitoring indeed encourages adolescents to engage less in problem behavior, it seems likely that they would offend less during those periods in which their parents monitor them more. A recent study, using about one third of the current sample, ${ }^{5}$ examined such within-individual effects of monitoring on delinquency (Keijsers, 2015). This study revealed no significant within-individual linkages between monitoring and delinquency.

In sum, the present study was among the first to examine within-individual associations between delinquency and monitoring. Despite the lack of prior research, we hypothesized (H2) on theoretical grounds that adolescents offend less during periods in which their parents exercise more solicitation and control than during other periods with less monitoring (i.e., within-individual effect). Moreover, we examined adolescents' disclosure (H3), which has consistently been associated with less problem behavior (e.g., Keijsers et al., 2010; Kerr et al., 2010).

\section{The interplay of monitoring and socioeconomic status}

Given that research findings on monitoring are not entirely consistent, recent studies have examined for whom monitoring may be effective and under what circumstances. Theoretically, it can be reasoned that monitoring is most effective when it is required by situational demands (Laird et al., 2010). For adolescents in high-risk environments, being protected by parents may be more important than perceiving autonomy. In these contexts, the benefits of monitoring may therefore outweigh the risk of perceived overprotection or privacy invasion. Adolescents may also be more likely to accept the legitimacy of monitoring in high-risk contexts (McElhaney \& Allen, 2001). Contrarily, adolescents in low-risk environments may more often perceive their parents' monitoring efforts as intrusive. Supporting this hypothesis, several between-individual studies have indeed suggested that whereas monitoring may be effective when adolescents are at risk for problem behavior, it may be ineffective or counter effective in the absence of risk factors such as unsupervised time and delinquent friends (Keijsers, Frijns, Branje, \& Meeus, 2009; Kiesner et al., 2010; Laird et al., 2010; Stattin \& Kerr, 2000).

Given that a low SES is among the core risk factors of delinquency literature (e.g., Bjerk, 2007; Merton, 1968; Rekker et al., 2015) and that monitoring has often appeared most effective in the presence of such risk factors, it seems plausible that the effect of monitoring may similarly be moderated by SES. The benefits of monitoring may outweigh the risk of perceived intrusion for low-SES adolescents, whereas the opposite could be true for high-SES adolescents. Potentially, more intrusive monitoring strategies such as parental control may therefore even be harmful for high-SES adolescents. Research on this potential moderation is presently limited to between-individual studies on parental knowledge about their children, as opposed to the active monitoring strategies distinguished by Stattin and Kerr (2000). These studies (Beyers, Bates, Pettit, \& Dodge, 2003; Pettit, Bates, Dodge, \& Meece, 1999; Rankin \& Quane, 2002; Roche \& Leventhal, 2009) have generally revealed a stronger betweenindividual association of more parental knowledge with less problem behavior among adolescents living in low-SES neighborhoods. The present study examined such a moderating role of SES within individuals over time. If monitoring is indeed more important for youths who are at risk for problem behavior, we may expect that especially low-SES adolescents offend less during periods in which their parents solicit and control more than during other periods with less monitoring.

In sum, the present study examined the interplay of SES with parental monitoring both between and within individuals. We hypothesized (H4) that the expected beneficial association of solicitation and control with delinquency would be stronger for low-SES adolescents than for high-SES adolescents. Contrarily, we did not expect such a moderating effect of SES for adolescents' disclosure of information. Whereas parental monitoring may plausibly be perceived as intrusive by high-SES adolescents, this reasoning does not apply to voluntary disclosure.

\section{The present study}

In conclusion, this study examined the interplay between monitoring and SES in predicting delinquency, both between adolescents and within adolescents. We expected delinquency to be associated with lower levels of parental solicitation and control between adolescents (H1) and potentially also within adolescents over time (H2). Furthermore, we hypothesized that delinquency would be associated with lower levels of adolescent disclosure (H3). Finally, we hypothesized that the beneficial association of solicitation and control, but not disclosure, with delinquency would be stronger among low-SES adolescents (H4).

\section{Method}

\subsection{Sample}

Analyses were conducted on six waves from the longitudinal 'Research on Adolescent Development and Relationships' (RADAR) study. Participants were 824 adolescents and their parents. Questionnaires were confidentially administered during annual home visits, for which the family received about $\$ 150$ per visit. Parents provided written informed consent for their

\footnotetext{
5 The study by Keijsers (2015) was a reanalysis of an earlier study (Keijsers et al., 2009) conducted on the adolescent reports in the first four waves of this study's 2001 cohort, reaching a total of 1308 observations. The present study was conducted on the full dataset of 4290 observations and uses all reporters.
} 
family's participation. A first cohort ( $N=327$; known as RADAR Old and as CONAMORE Family Sample) was first interviewed in 2001, while a second cohort was first interviewed in 2005 ( $N=497$; known as RADAR Young). All respondents were enrolled in the first year of secondary education during the first wave $\left(M_{\text {age }}=12.7 ; S D_{\text {age }}=0.62\right)$. The first two waves of the 2001 cohort were excluded from the analyses, due to the absence of parent reports on monitoring. The sample consisted of $53.6 \%$ boys and $46.4 \%$ girls. Adolescents' educational level was distributed $25.8 \%$ lower vocational, $33.5 \%$ higher vocational, and $40.7 \%$ pre-academic. Parents' educational level was $27.0 \%$ lower vocational, 39.5\%, higher vocational, and $33.5 \%$ academic. These distributions indicate that respondents had a higher average SES than the general population of the Netherlands (CBS, 2005). Furthermore, nearly all respondents were of native Dutch ethnicity. Differences between the RADAR sample and the general population of the Netherlands can be attributed to the geographical restriction to the Utrecht province and nearby cities, an inclusion criteria of a good Dutch language comprehension, and the exclusion of single parent families.

\subsection{Measures}

Delinquency. At each wave, delinquency was measured as the variety count of offenses that an adolescent committed during the previous year. Adolescents self-reported these offenses on a 32-item scale of illegal behaviors that included the use of drugs, but not the use of alcohol or tobacco. Items were based on the International Self-Report Delinquency Study (JungerTas, Terlouw, \& Klein, 1994) and validated for Dutch adolescents in previous studies (Baerveldt, Van Rossem, \& Vermande, 2003). An example of an item is "During the past year, did you steal something from a shop worth over 5 euro?" Nearly all reported behaviors were relatively minor offenses such as vandalism, shoplifting, and drug use. For the 2001 cohort, a shortened scale was administered during waves 3, 4, and 5. This 16-item questionnaire covered the same offenses, but with less specificity. For example, it included only a single item on shoplifting (i.e., stealing something), whereas the main questionnaire included two items (i.e., stealing something under and over 5 euro). During the fifth wave, 233 respondents completed both the shortened and the complete scale. The association between both scales was strong $(r=0.84)$. To adjust for the smaller number of items in the shortened questionnaire, scores were rescaled to the metric of the full questionnaire using the following formula: 'estimated score on full questionnaire $=0.41+1.03$ * score on shortened questionnaire'. The coefficients of this formula were obtained from a regression analysis among the 233 respondents who completed both questionnaires to make sure that the rescaled scores reflect the best possible estimates of the score that respondents would have obtained if they had completed the full questionnaire.

Monitoring and disclosure. This study combined multi-informant data on monitoring and disclosure from three different reporters into a single composite score for every adolescent. Solicitation, control, and disclosure were reported by adolescents, mothers, and fathers. Scores of mothers and fathers were first averaged into a parent report, while reports of adolescents on mothers and fathers were averaged into an adolescent report. ${ }^{6}$ The parent and adolescent reports were in turn averaged to obtain a single score on each construct that equally reflects the perspective of adolescents and both parents. Items were based on the work of Stattin and Kerr (2000). Previous studies have demonstrated the validity of these measures for a Dutch sample (Hawk et al., 2008). Parental solicitation was measured using 3 items, such as: "Do you commonly ask your child to tell about things that happened during his/her free time?" Reliability averaged $\alpha=.67$ across waves for mothers, .72 for fathers, and .74 for adolescents. The consistency of reported solicitation averaged $r=.12$ between mothers and fathers and .21 between parents and adolescents. Parental control was assessed using 5 items. An example is "Before your child goes out on a Saturday evening, do you demand him/her to inform you about where he/she is going and with whom?" Reliability averaged $\alpha=.85$ across waves for mothers, fathers, and adolescents a like. The consistency of reported control averaged $r=$ .25 between mothers and fathers and .37 between parents and adolescents. Adolescent disclosure was measured using 6 items, for instance: "If you have been away during the evening, do you tell your parents what you have done when you come home?" Reliability averaged $\alpha=.80$ across waves for mothers, .77 for fathers, and .77 for adolescents. The consistency of reported disclosure averaged $r=.47$ between mothers and fathers and .50 between parents and adolescents. Solicitation, control, and disclosure were scored on a scale ranging from 1 (never) to 5 (always) and standardized to facilitate the interpretation of parameter estimates. Because scales' reliabilities were sufficient, the relatively low consistencies between mothers, fathers, and adolescents underline the distinct perspective of each reporter.

Socioeconomic status. This study distinguished three facets of SES: adolescents' educational level, parents' educational level, and neighborhood SES. Adolescents' educational level constituted the self-reported track in which they were enrolled at the fifth wave. Parental educational level was indicated by the highest self-reported educational level completed by either of the two parents. Educational level was analyzed as a scale with three scores - 1: (lower vocational; i.e., VMBO/MBO), 0 (higher vocational, i.e., HAVO/HBO), and 1 (pre-academic, i.e., VWO/University). Information on neighborhoods was obtained from the Dutch Central Bureau of Statistics (CBS, 2006; 2011), based on respondents six-digit postal code (comparable to American census tracts) at the first wave. Neighborhood SES was a standardized sum score of neighborhoods' standardized population density, mean fiscal income, and mean property value. In all analyses, we specified SES as a single composite by adding standardized scores on parental education, neighborhood SES, and adolescent education. Scores on this composite were in turn also standardized.

\footnotetext{
${ }^{6}$ At wave 3 and 4 of the 2001 cohort, adolescents reported on both parents simultaneously. A comparison between these scores and scores that were reported for mothers and fathers separately revealed no discontinuities in mean levels, associations across waves, or associations between constructs.
} 
Table 1

Descriptive statistics and bivariate between-individual correlations (Pearson's r).

\begin{tabular}{|c|c|c|c|c|c|c|c|c|c|c|c|c|c|c|}
\hline \multirow[t]{2}{*}{ Variable } & \multicolumn{7}{|c|}{ Between Individuals } & \multirow{2}{*}{$\frac{\text { Wave } 1}{\mathrm{M}(\mathrm{SD})}$} & \multirow{2}{*}{$\frac{\text { Wave } 2}{\mathrm{M}(\mathrm{SD})}$} & \multirow{2}{*}{$\frac{\text { Wave } 3}{\mathrm{M}(\mathrm{SD})}$} & \multirow{2}{*}{$\frac{\text { Wave } 4}{\mathrm{M}(\mathrm{SD})}$} & \multirow{2}{*}{$\frac{\text { Wave } 5}{\mathrm{M}(\mathrm{SD})}$} & \multicolumn{2}{|l|}{ Wave 6} \\
\hline & 2 & 3 & 4 & 5 & 6 & $\mathrm{M}(\mathrm{SD})$ & $\mathrm{N}$ & & & & & & $\mathrm{M}(\mathrm{SD})$ & ICC \\
\hline $\begin{array}{l}\text { 1. Delinquency } \\
\text { 2. SES }\end{array}$ & $-.15^{* * * *}$ & $\begin{array}{l}.12^{* * * *} \\
.28^{* * *}\end{array}$ & $\begin{array}{l}-.12^{* * *} \\
.15^{* * *}\end{array}$ & $\begin{array}{l}-.41^{* * * *} \\
.15^{* * *}\end{array}$ & $\begin{array}{l}-.24^{* * * *} \\
.01\end{array}$ & $\begin{array}{l}1.54(1.92) \\
0.00(1.00)\end{array}$ & $\begin{array}{l}824 \\
823\end{array}$ & $1.91(3.21)$ & $1.30(2.68)$ & $1.50(2.68)$ & $1.52(2.81)$ & $1.42(2.51)$ & $1.40(2.94)$ & .44 \\
\hline 3. Solicitation & & & $.34^{* * *}$ & $.54^{* * *}$ & $.10^{* *}$ & $0.00(1.00)$ & 824 & $0.25(1.00)$ & $0.07(1.03)$ & $-0.06(0.92)$ & $-0.02(0.98)$ & $-0.02(1.02)$ & $-0.13(1.05)$ & .56 \\
\hline 4. Control & & & & $.21^{* * * *}$ & $.18^{* * *}$ & $0.00(1.00)$ & 813 & $0.70(0.73)$ & $0.52(0.75)$ & $0.38(0.79)$ & $0.11(0.85)$ & $-0.33(0.94)$ & $-0.88(0.96)$ & .33 \\
\hline 5. Disclosure & & & & & $.28^{* * *}$ & $0.00(1.00)$ & 824 & $0.37(0.90)$ & $0.18(0.98)$ & $0.02(0.92)$ & $-0.11(1.01)$ & $-0.15(1.03)$ & $-0.14(1.05)$ & .64 \\
\hline 6. Gender & & & & & & $0.46(0.50)$ & 824 & & & & & & & \\
\hline
\end{tabular}

Note. ${ }^{*} \mathrm{p}<.05 .{ }^{* *} \mathrm{p}<.01 .{ }^{* * *} \mathrm{p}<.001$. ICC: intraclass correlation (i.e., proportion of variance at between-individual level). Scores on SES, solicitation, control, and disclosure were standardized across waves. 
Negative binomial regression models predicting adolescent delinquency.

\begin{tabular}{|c|c|c|c|c|c|c|}
\hline & \multicolumn{3}{|c|}{ Between-individual Models } & \multicolumn{3}{|c|}{ Within-individual Models } \\
\hline & Model 1 & Model 2 & Model 3 & Model 1 & Model 2 & Model 3 \\
\hline Gender: Female & $-0.62(0.08)^{* * * *}$ & $-0.62(0.08)^{* * * *}$ & $-0.38(0.08)^{* * * *}$ & & & \\
\hline Socioeconomic Status & $-0.20(0.04)^{* * *}$ & $-0.20(0.04)^{* * *}$ & $-0.18(0.04)^{* * *}$ & & & \\
\hline Parental Solicitation & $-0.08(0.04)$ & $-0.07(0.04)$ & $0.24(0.05)^{* * *}$ & $-0.03(0.04)$ & $-0.04(0.04)$ & $0.06(0.04)$ \\
\hline Parental Control & $-0.06(0.04)$ & $-0.05(0.04)$ & $-0.04(0.04)$ & $0.10(0.05)^{*}$ & $0.09(0.05)$ & $0.10(0.04)^{*}$ \\
\hline SES*Solicitation & & $0.02(0.05)$ & $0.02(0.04)$ & & $-0.01(0.04)$ & $0.00(0.04)$ \\
\hline SES*Control & & $0.01(0.04)$ & $-0.00(0.04)$ & & $-0.08(0.03)^{*}$ & $-0.05(0.03)$ \\
\hline Adolescent Disclosure & & & $-0.56(0.05)^{* * * *}$ & & & $-0.46(0.04)^{* * *}$ \\
\hline Delinquency $\mathrm{t}_{-1}$ & & & & $0.01(0.01)$ & $0.01(0.01)$ & $0.01(0.01)$ \\
\hline \multicolumn{7}{|l|}{ Model } \\
\hline Respondents & 812 & 812 & 812 & 796 & 795 & 795 \\
\hline Observations & 812 & 812 & 812 & 2919 & 2916 & 2916 \\
\hline Pseudo $\mathrm{R}^{2}$ & $3.38 \%$ & $3.40 \%$ & $8.59 \%$ & & & \\
\hline
\end{tabular}

Note. ${ }^{*} \mathrm{p}<.05 .{ }^{* *} \mathrm{p}<.01 .{ }^{* * *} \mathrm{p}<.001$. Coefficients are unstandardized with standard errors in parentheses. Dummy variables controlling for cohort, questionnaire type, wave, and respondent (i.e., fixed effects) are omitted from the table.

\subsection{Strategy of analysis}

Estimation method. Since our delinquency measure revealed a negative binomial count distribution (score 0: $31.4 \%$; score 1: 35.4\%; score 2-16: 33.1\%; variance-to-mean ratio: 2.4 ), we analyzed data using negative binomial regression analysis with maximum likelihood estimation. Analyses were carried out separately between and within adolescents. For the betweenindividual analyses, our goal was to determine if some adolescents offended more than others during the entire course of adolescence. For this purpose, we calculated individual mean scores across all waves on delinquency, solicitation, control, and disclosure. These means were calculated across all six waves for the 2005 and (due to available data) from wave 3 through wave 6 for the 2001 cohort. For delinquency, mean scores were rounded to integers to maintain the count distribution. SES variables were time-constant throughout this study. Using these mean scores, we carried out negative binomial regression analyses to estimate fully between-individual effects. For the within-individual estimation, we used fixed-effects negative binomial regression analyses ${ }^{7}$ (Hausman, Hall, \& Griliches, 1984). Fixed-effects models capture only within-individual variation by examining changes around respondents' average scores across waves. This allowed us to examine how overtime fluctuations in monitoring and disclosure co-occurred with parallel fluctuations in delinquency.

Model specification. Model specification was based on two principles. First, variables' main effects cannot be estimated in models that also include an interaction term of that variable (Brambor, Clark, \& Golder, 2006). Second, variables' effects cannot be estimated in a model that controls for mediators of these effects (Pearl, 2000). These two principles resulted in a four-step model specification. A first model estimated main effects of parental solicitation and control. Adolescent disclosure was excluded from this model, because it may mediate beneficial monitoring effects ${ }^{8}$ (Soenens et al., 2006). A second model added interactions between SES and monitoring. A third model added adolescent disclosure and a fourth model subsequently added interactions between disclosure and SES.

Control variables. Using dummy variables, between-individual analyses were controlled for gender and cohort (2001/ 2005). These variables did not require inclusion in the within-individual analyses, since fixed-effects models automatically control for all time-constant variables. Instead, within-individual models were controlled for age (i.e., the age-crime curve; Farrington, 1986), which was accomplished using a set of dummy variables indicating the wave. To control for potential bias from a change in the delinquency questionnaire for the 2001 cohort, a dummy variable was added that indicated the administered instrument. In addition, within-individual models included a time-lagged delinquency variable to control for delinquency at the previous wave.

Attrition and missing values. Attrition was low and occurred mainly between wave 5 ( $91 \%$ participating) and wave 6 ( $80 \%$ participating). We assessed the amount of missing values across all 4290 observations: 327 respondents on 4 waves for the 2001 cohort and 497 respondents on 6 waves for the 2005 cohort. The percentage of missing values on each variable was as follows: delinquency $10.4 \%$, socioeconomic status $0.1 \%$, solicitation $9.5 \%$, control $14.8 \%$, and disclosure $9.5 \%$. An MCAR test revealed a good $\mathrm{Chi}^{2} / \mathrm{df}$ ratio of 1.43 (Bollen, 1989), which indicates that missing values were not strongly associated with scores on other variables. For the between-individual analyses, all waves with data could be used to calculate respondents' across-wave mean scores. A small adjustment was made for waves with missing data to approximate the score that

\footnotetext{
7 Fixed-effects models were estimated using an unconditional negative binomial regression estimator with dummy variables to represent the fixed effects, since conditional negative binomial models may not exclusively capture within-individual variation (Allison \& Waterman, 2002).

8 There are at least three conceivable causal sequences between the constructs under study: Monitoring - > Disclosure - > Delinquency (1), Delinquency - > Disclosure < - Monitoring (2), and Delinquency < - Disclosure - > Monitoring (3). Controlling for disclosure while estimating effects of monitoring on delinquency would only improve estimates if the third causal sequence (i.e., common cause) is accurate. If either the first (i.e., mediational chain) or the second sequence (i.e., collider effect) is correct, controlling for disclosure would contrarily bias the total effects of monitoring on delinquency (Pearl, 2000).
} 
respondents would have obtained across all six waves. ${ }^{9}$ Due to the estimation method, all respondents who had complete data on at least one wave could be included in the within-individual analyses (i.e., complete case analysis in long notation).

\section{Results}

Descriptive statistics and bivariate correlations for all constructs are displayed in Table 1. Model specification proceeded in four steps, as displayed in Table 2. To investigate the main effects of solicitation and control, a first model was specified without moderating or mediating (i.e., disclosure) effects. Between individuals, parental solicitation and control were not significantly associated with adolescent delinquency. This rejected our hypothesis (H1) that adolescents whose parents exercise more monitoring would offend less than others. Noticeably, both solicitation and control revealed a negative bivariate correlation with delinquency (see Table 1), but these associations were no longer significant after controlling for gender and SES.

Within individuals, solicitation revealed no significant effect on delinquency, whereas control revealed a positive effect that was opposite to our hypothesis. This rejected our hypothesis (H2) that more monitoring would be associated with less delinquency within adolescents over time. Contrarily, adolescents even offended more during periods in which their parents exercised more control than during other periods with less control.

To assess how parental monitoring effects may be moderated by SES, we added interactions between SES and monitoring in a second model. Between individuals, we found no significant interaction of SES with either solicitation or control. Within individuals, we found a significant interaction of SES with parental control. Importantly, this interaction was in the opposite direction of what was expected: Higher levels of control co-occurred with higher levels of delinquency primarily among lowSES adolescents (see Fig. 1). These findings clearly refuted our hypothesis (H4) that the association between monitoring and delinquency would be more beneficial for low-SES adolescents. Contrarily, an interaction was found only within adolescents and in the opposite direction. To determine how this interaction may be interpreted, we estimated the effect of parental control for low (z-score of -1 ) and high (z-score of +1 ) levels of SES using a simple slopes analysis (Cohen, Cohen, West, \& Aiken, 2003). As depicted in Fig. 1, this analysis revealed that control was associated with more delinquency for low-SES adolescents $(b=0.16, p=.002)$, but not for high-SES adolescents $(b=0.01, p=.862)$.

To investigate if interactions with SES are specific to parents' efforts, we specified a third model that added adolescent disclosure. As expected (H3), we found a strong negative effect of disclosure on delinquency both between and within individuals. In line with previous studies, adding disclosure changed the direction of the between-individual effect of solicitation (from -0.07 to +0.24 ). In a fourth model (omitted from Table 2), we added and tested an interaction between disclosure and SES. In line with our theoretical reasoning that SES moderation is specific to parental monitoring, this interaction was non-significant both between and within adolescents.

\subsection{Internal replication}

To check the reliability of these findings, we performed three additional analyses. First, we repeated all analyses separately for adolescent, mother, and father reports (see Appendix A). Results demonstrated consistent patterns across reporters. The within-individual effect of parental control was significant for mother $(b=0.11, p=.009)$ and father reports $(b=0.10, p=$ $.016)$, but non-significant for adolescent reports $(b=0.03, p=.501)$. The within-individual interaction between SES and parental control was significant for mother reports $(b=-0.08, p=.018)$, marginally significant for father reports $(b=-0.06, p$ $=.071)$, and non-significant for adolescent reports $(b=-0.04, p=.242)$. The negative effect of adolescent disclosure on delinquency was significant for all three reporters, both between and within adolescents. A formal comparison revealed no significant differences in effect sizes between reporters for any of this study's significant findings.

Second, we repeated our analyses with adolescent disclosure as outcome variable (see Appendix B). Based on the idea that effects of monitoring on delinquency may be mediated by disclosure (e.g., Soenens et al., 2006), we expected that results for disclosure would resemble those for delinquency. Consistently, core findings were replicated for adolescent disclosure. Within-individual analyses revealed the same interaction between SES and parental control that was found for adolescent delinquency. However, parental solicitation was decisively associated with more adolescent disclosure both between and within individuals, whereas its association with delinquency was non-significant.

Because previous studies focused specifically on between-individual moderation by neighborhoods (e.g., Beyers et al., 2003), we finally ran an analysis in which neighborhood quality (instead of an SES composite) was specified as a betweenindividual moderator. In line with previous studies, this analysis revealed an interaction $(b=0.11, p=.046)$ in which more parental control was associated with less delinquency particularly in low-SES neighborhoods. This suggests that differences

\footnotetext{
${ }^{9}$ In the calculation of respondents' across-wave mean score, missing values were replaced by a predicted score from a regression model in which the score on the wave with missing data was the dependent variable, and the score on the previous wave was the independent variable. In addition, mean scores for the 2001 cohort were corrected for the absence of the first two waves, using coefficients that were obtained from a regression analysis on the 2005 cohort. Correlations between adjusted and unadjusted scores varied between $r=0.97$ and .99 across variables. An exploratory analysis with unadjusted scores revealed no meaningful differences with the reported results.
} 


\section{Between Individuals}

\section{Parental Control}

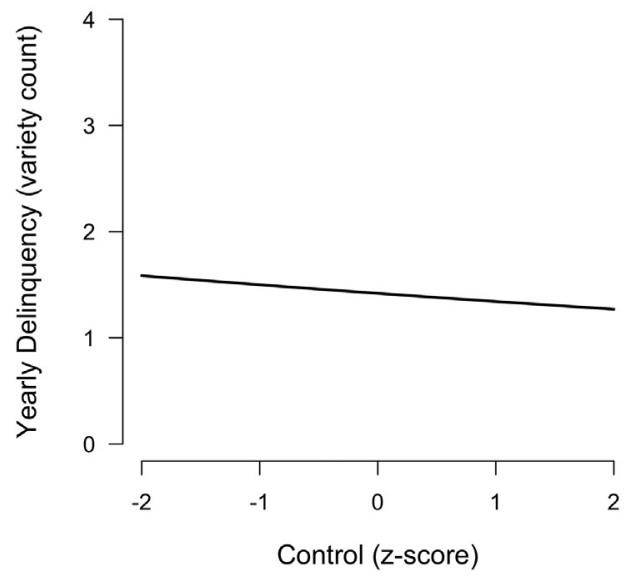

Adolescent Disclosure

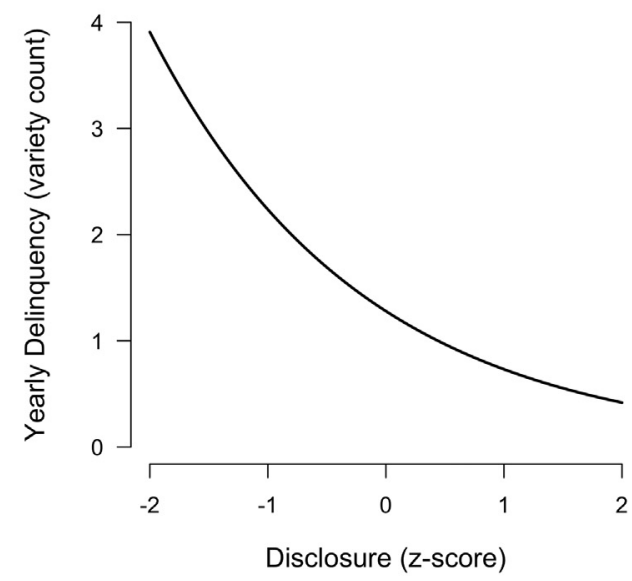

Within Individuals

\section{Parental Control}

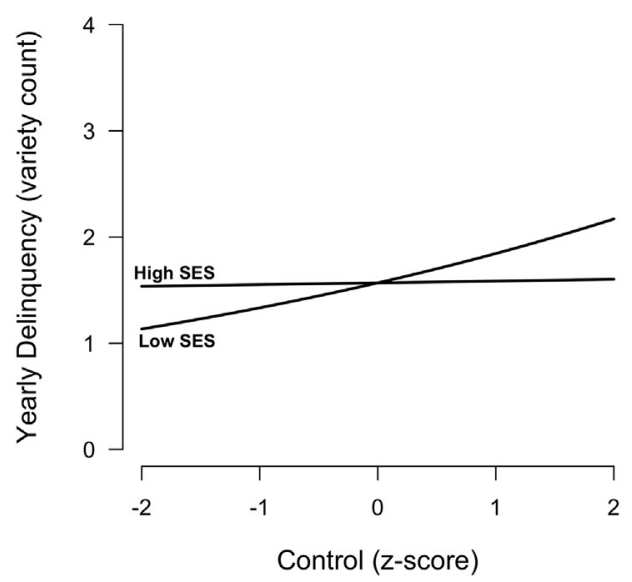

Adolescent Disclosure

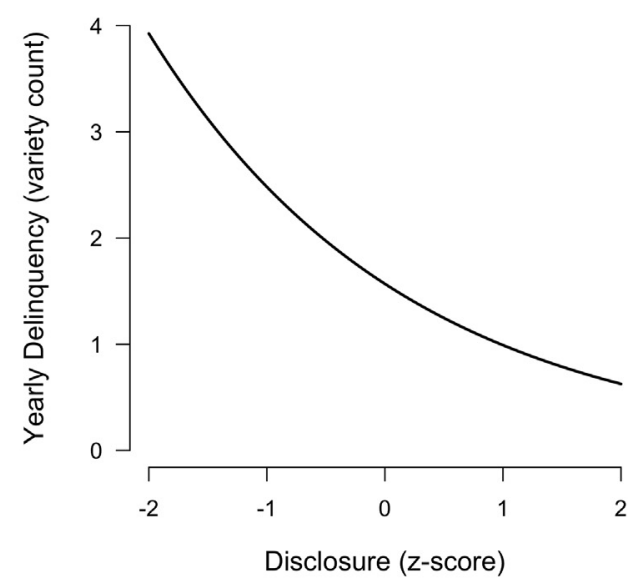

Fig. 1. Effects as estimated in between-individual models 1 (control) and 3 (disclosure) and within-individual models 2 (control) and 3 (disclosure). Estimated levels of delinquency are unique for each respondent and each year in the within-individual model. This graph therefore depicts effects for a hypothetical respondent and year, with delinquency close to the mean level. Low SES: $z$-score of -1 ; High SES: $z$-score of +1 .

between this study and previous findings are due to the use of multiple SES components and particularly within-individual modelling.

\section{Discussion}

This study examined the interplay between socioeconomic status and parental monitoring in predicting minor adolescent delinquency. Results revealed that this interplay is different within adolescents across time than between adolescents. Between individuals, parental solicitation and control were not significantly associated with adolescent delinquency after controlling for SES. Within individuals, higher levels of parental control were unexpectedly associated with higher levels of adolescent delinquency, but this relation was dependent on SES: Low-SES adolescents, but not high-SES adolescents, offended more during periods in which their parents exercised more control than during other periods with less control. Unlike parental monitoring, adolescent disclosure was strongly associated with less delinquency both between and within adolescents and regardless of SES.

These results strongly contradicted our hypothesis that monitoring would be related to less delinquency. Many previous studies (e.g., Stattin \& Kerr, 2000) revealed between-individual associations of more solicitation and control with less 
delinquency. Although this study revealed similar correlations at the bivariate level (Table 1 ), these associations were reduced to non-significance by controlling for gender and SES. The strongest contradiction with our hypothesis and previous literature (e.g., Stattin \& Kerr, 2000) was however posed by the finding that control was overall linked to more delinquency within individuals. Challenging the idea that monitoring can preclude delinquent behavior, this finding implies that adolescents offended more when their parents exercised higher levels of control than during other periods with less control. This might indicate that adolescents become more delinquent in response to parents' increased control, or that parents increase supervision when their children go astray. Unlike delinquency, adolescent disclosure was however decisively associated with higher levels of solicitation both between and within adolescents, which suggests that solicitation could nonetheless have beneficial effects.

We see three possible interpretations for the discrepancy between results at the between- and the within-individual level. The first is that it could be beneficial when parents consequently exercise higher levels of monitoring than other parents from childhood onwards (i.e., between-individual differences), whereas it could be harmful when the same parents monitor their child more than usual during a particular period (i.e., within-individual differences). A second explanation is that the association between monitoring and delinquency is not causal, but due to some time-constant third variable affecting both monitoring and delinquency (e.g., genetic predisposition). Unlike between-individual models, within-individual models control for such time-constant third variables. In line with this explanation, between-individual associations between monitoring and delinquency were no longer significant after controlling for gender and SES. A third interpretation of the discrepancy between between-individual and within-individual patterns lies in potential harmful dynamics between parenting and problem behavior. For example, Granic and Patterson (2006) theorized that families can get trapped in a process in which children's negative behavior (e.g., delinquency) provokes coercive parenting (e.g., too much control), which in turn leads to more negative behavior. Since such dynamic processes take place within families over time, they may be visible particularly at the within-individual level.

Unlike parental solicitation and control, adolescents' voluntary disclosure was strongly associated with less delinquency both between and within adolescents. This finding is consistent with previous studies that found a within-individual association between parental knowledge and delinquency (e.g., Farrington et al., 2002), while also suggesting that these findings may be accounted for by disclosure, more than by monitoring. Interestingly, the association between solicitation and delinquency reversed after controlling for disclosure. This finding is consistent with the idea that beneficial effects of monitoring are mediated by disclosure (Soenens et al., 2006). When parents ask more, but adolescents nonetheless do not tell more (the effect of solicitation while keeping disclosure constant), this potentially indicates a heightened engagement in problem behavior. Parents could be asking more questions in these situations precisely because they suspect that their child may be withholding information about risky activities.

Besides distinguishing between- and within-individual effects, the main aim of this study was to examine how the relation between monitoring and delinquency may depend on SES. Based on between-individual analyses, previous studies revealed that monitoring is most likely to be associated with less delinquency in high-risk contexts (e.g., Laird et al., 2010). Instead, the present study revealed that monitoring interacted with SES only within individuals and in the opposite direction. This study therefore challenges claims (e.g., Laird et al., 2010) that monitoring is most effective in high-risk environments, by demonstrating that this may be reversed within adolescents across time.

The within-individual finding that higher levels of parental control more often co-occurred with higher levels of delinquency among low-SES adolescents than among high-SES adolescents was unexpected. One feasible explanation is that high-SES parents more often exercise a warm, open, and authoritative style of parenting (Conger, Ge, Elder, Lorenz, \& Simons, 1994; Steinberg, Mounts, Lamborn, \& Dornbusch, 1991). Potentially, parental control is more likely to be perceived as legitimate by adolescents in such a climate (Darling \& Steinberg, 1993; Kuhn, Phan, \& Laird, 2014). Likewise, negative dynamics between parenting and delinquency could occur more often among low-SES parents who may be more likely to respond to negative behavior with coercive parenting (Conger et al., 1994). Speculatively, high-SES parents may thus be more successful in exercising parental control by providing structure, whereas low-SES parents could more often use pressure, thereby instigating feelings of intrusion among adolescents (e.g., Soenens \& Vansteenkiste, 2010). In addition, especially lowSES parents could become overcontrolling when their children become delinquent.

Despite this uncertainty about the explanatory mechanism, this study's within-individual analyses suggest that monitoring could be less effective in low-SES contexts. Although such causal inferences remain speculative without an experimental design, this study's within-individual analyses may come slightly closer to causality than between-individual models by for example controlling for all time-constant third variables (Molenaar \& Campbell, 2009; Voelkle et al., 2014). Hence, monitoring could contribute to the relation between SES and delinquency by being both less often exercised and less effective for low-SES adolescents.

\subsection{Strengths and limitations}

Strengths of this study include the use of multi-informant data and analyses that distinguish between- and withinindividual effects. A first limitation was that most respondents had an above average SES, for example due to the exclusion of single parent families. Caution is therefore warranted in generalizing findings to more extreme low-SES contexts. Because the Netherlands is a prosperous nation with a well-developed social security system, caution is particularly warranted in generalizing this study's findings to the poorest families and neighborhoods in the United States. Instead, this study 
might better be translated to the American context as a comparison between lower middle class and higher middle class families. Second, this study investigated associations, rather than bidirectional effects. Although it is known that monitoring and delinquency may be reciprocally related (e.g., Keijsers et al., 2010), this study instead focused on distinguishing betweenand within-individual effects. We partly interpreted our findings in terms of child-driven effects (i.e., from delinquency on monitoring), but it should be emphasized that our statistical design did not allow us to distinguish such reversed effects from those of monitoring on delinquency. Future research is needed, preferably with more waves and smaller time intervals, to assess both research questions simultaneously.

\subsection{Conclusion}

Despite these limitations, this study challenged the idea that monitoring is more effective in high-risk contexts by demonstrating a within-individual interaction between parental control and SES in the opposite direction. Low-SES adolescents, but not high-SES adolescents, offended more during periods in which their parents exercised more control than during other periods with less control. This suggests that parental monitoring could be least effective when needed most. Low-SES parents might not use monitoring effectively and become overcontrolling when their child goes astray.

\section{Acknowledgements}

This research was supported by a grant from the Coordinating Societal Change program of Utrecht University. In the present study, data of the RADAR study were used. RADAR has been financially supported by main grants from the Netherlands Organisation for Scientific Research (GB-MAGW 480-03-005; GB-MAGW 480-08-006), and Stichting Achmea Slachtoffer en Samenleving (SASS), a grant from the Netherlands Organisation for Scientific Research to the Consortium Individual Development (CID; 024.001.003), and various other grants from the Netherlands Organisation for Scientific Research (NWO), the Free University of Amsterdam (VU), and Utrecht University.

\section{Appendix A. Supplementary data}

Supplementary data related to this article can be found at http://dx.doi.org/10.1016/j.adolescence.2017.06.001.

\section{References}

Agnew, R. (1984). Autonomy and delinquency. Sociological Perspectives, 27, 219-240. http://dx.doi.org/10.2307/1389019.

Allison, P. D., \& Waterman, R. P. (2002). Fixed-effects negative binomial regression models. Sociological Methodology, 32, 247-265. http://dx.doi.org/10.1111/ 1467-9531.00117.

Baerveldt, C., Van Rossem, R., \& Vermande, M. (2003). Pupils' delinquency and their social networks: A test of some network assumptions of the ability and inability models of delinquency. Netherlands' Journal of Social Sciences, 39, 107-125.

Beyers, J. M., Bates, J. E., Pettit, G. S., \& Dodge, K. A. (2003). Neighborhood structure, parenting processes, and the development of youths' externalizing behaviors: A multilevel analysis. American Journal of Community Psychology, 31, 35-53. http://dx.doi.org/10.1023/a:1023018502759.

Bjerk, D. (2007). Measuring the relationship between youth criminal participation and household economic resources. Journal of Quantitative Criminology, 23, 23-39. http://dx.doi.org/10.1007/s10940-006-9017-8.

Bollen, K. A. (1989). Structural equations with latent variables. New York: Wiley.

Brambor, T., Clark, W. R., \& Golder, M. (2006). Understanding interaction models: Improving empirical analyses. Political Analysis, 14, 63-82. http://dx.doi. org/10.1093/pan/mpi014.

CBS. (2005). Nederlandse bevolking steeds hoger opgeleid [Dutch population increasingly educated]. CBS Webmagazine, July $25,2005$.

CBS. (2006). Kerncijfers postcodegebieden 2004 [Key figures for postcode areas 2004]. Statistics Netherlands, The Hague.

CBS. (2011). Kerncijfers postcodegebieden 2008-2010 [Key figures for postcode areas, 2008-2010]. Statistics Netherlands, The Hague.

Cohen, J., Cohen, P., West, S. G., \& Aiken, L. S. (2003). Applied multiple regression/correlation analysis for the behavioral sciences (3rd ed.). Hillsdale, NJ: Erlbaum.

Conger, R. D., Ge, X., Elder, G. H., Lorenz, F. O., \& Simons, R. L. (1994). Economic stress, coercive family process, and developmental problems of adolescents. Child Development, 65, 541-561. http://dx.doi.org/10.2307/1131401.

Darling, N., \& Steinberg, L. (1993). Parenting style as context: An integrative model. Psychological Bulletin, 113, 487-496. http://dx.doi.org/10.1037//00332909.113.3.487.

Dishion, T. J., \& McMahon, R. J. (1998). Parental monitoring and the prevention of child and adolescent problem behavior: A conceptual and empirical formulation. Clinical Child and Family Psychology Review, 1, 61-75. http://dx.doi.org/10.1023/a:1021800432380.

Farrington, D. P. (1986). Age and crime. Crime and Justice, 7, 189-250. http://dx.doi.org/10.1086/449114.

Farrington, D. P., Loeber, R., Yin, Y., \& Anderson, S. J. (2002). Are within-individual causes of delinquency the same as between-individual causes? Criminal Behaviour and Mental Health, 12, 53-68. http://dx.doi.org/10.1002/cbm.486.

Fletcher, A. C., Steinberg, L., \& Williams-Wheeler, M. (2004). Parental influences on adolescent problem behavior: Revisiting Stattin and Kerr. Child Development, 75, 781-796. http://dx.doi.org/10.1111/j.1467-8624.2004.00706.x.

Granic, I., \& Patterson, G. R. (2006). Toward a comprehensive model of antisocial development: A dynamic systems approach. Psychological Review, 113, 101-131. http://dx.doi.org/10.1037/0033-295x.113.1.101.

Grolnick, W. S., \& Pomerantz, E. M. (2009). Issues and challenges in studying parental control: Toward a new conceptualization. Child Development Perspectives, 3, 165-170. http://dx.doi.org/10.1111/j.1750-8606.2009.00099.x.

Hamaker, E. L., Kuiper, R. M., \& Grasman, R. P. (2015). A critique of the cross-lagged panel model. Psychological Methods, 20, 102-116. http://dx.doi.org/10. 1037/a0038889.

Hausman, J. A., Hall, B. H., \& Griliches, Z. (1984). Econometric models for count data with an application to the patents-R\&D relationship. Econometrica, 52, 909-938. http://dx.doi.org/10.2307/1911191.

Hawk, S. T., Hale, W. W., Raaijmakers, Q. A. W., \& Meeus, W. (2008). Adolescents' perceptions of privacy invasion in reaction to parental solicitation and control. Journal of Early Adolescence, 28, 583-608. http://dx.doi.org/10.1177/0272431608317611. 
Junger-Tas, J., Terlouw, G., \& Klein, M. W. (1994). Delinquent behavior among young people in the western world. In First results of the international selfreport delinquency study. Amsterdam: Kugler Publications.

Kakihara, F., \& Tilton-Weaver, L. (2009). Adolescents' interpretations of parental control: Differentiated by domain and types of control. Child Development, 80, 1722-1738. http://dx.doi.org/10.1111/j.1467-8624.2009.01364.x.

Keijsers, L., Frijns, T., Branje, S. J. T., \& Meeus, W. (2009). Developmental links of adolescent disclosure, parental solicitation, and control with delinquency: Moderation by parental support. Developmental Psychology, 45, 1314-1327. http://dx.doi.org/10.1037/a0016693.

Keijsers, L., Branje, S. J., VanderValk, I. E., \& Meeus, W. (2010). Reciprocal effects between parental solicitation, parental control, adolescent disclosure, and adolescent delinquency. Journal of Research on Adolescence, 20, 88-113. http://dx.doi.org/10.1111/j.1532-7795.2009.00631.x.

Keijsers, L. (2015). Parental monitoring and adolescent problem behaviors How much do we really know? International Journal of Behavioral Development. http://dx.doi.org/10.1177/0165025415592515.

Kerr, M., \& Stattin, H. (2000). What parents know, how they know it, and several forms of adolescent adjustment: Further support for a reinterpretation of monitoring. Developmental Psychology, 36, 366-380. http://dx.doi.org/10.1037//0012-1649.36.3.366.

Kerr, M., Stattin, H., \& Burk, W. J. (2010). A reinterpretation of parental monitoring in longitudinal perspective. Journal of Research on Adolescence, $20,39-64$. http://dx.doi.org/10.1111/j.1532-7795.2009.00623.x.

Kiesner, J., Dishion, T. J., Poulin, F., \& Pastore, M. (2009). Temporal dynamics linking aspects of parent monitoring with early adolescent antisocial behavior. Social Development, 18, 765-784. http://dx.doi.org/10.1111/j.1467-9507.2008.00525.x.

Kiesner, J., Poulin, F., \& Dishion, T. J. (2010). Adolescent substance use with friends moderating and mediating effects of parental monitoring and peer activity contexts. Merrill-Palmer Quarterly, 56, 529-556. http://dx.doi.org/10.1353/mpq.2010.0002.

Klevens, J., \& Hall, J. (2014). The importance of parental warmth, support, and control in preventing adolescent misbehavior. Journal of Child and Adolescent Behavior, 2, 1-8. http://dx.doi.org/10.4172/jcalb.1000121.

Kuhn, E. S., Phan, J. M., \& Laird, R. D. (2014). Compliance with parents' rules: Between-person and within-person predictions. Journal of Youth and Adolescence, 43, 245-256. http://dx.doi.org/10.1007/s10964-013-9965-x.

Laird, R. D., Marrero, M. D., \& Sentse, M. (2010). Revisiting parental monitoring: Evidence that parental solicitation can be effective when needed most. Journal of Youth and Adolescence, 39, 1431-1441. http://dx.doi.org/10.1007/s10964-009-9453-5.

Lam, C. B., McHale, S. M., \& Crouter, A. C. (2014). Time with peers from middle childhood to late adolescence: Developmental course and adjustment correlates. Child Development, 85, 1677-1693. http://dx.doi.org/10.1111/cdev.12235.

Larson, R., \& Richards, M. H. (1991). Daily companionship in late childhood and early adolescence: Changing developmental contexts. Child Development, 62, 284-300. http://dx.doi.org/10.1111/j.1467-8624.1991.tb01531.x.

McElhaney, K. B., \& Allen, J. P. (2001). Autonomy and adolescent social functioning: The moderating effect of risk. Child Development, 72(1), 220-235. http:// dx.doi.org/10.1111/1467-8624.00275.

Merton, R. K. (1968). Social theory and social structure. New York: University Press.

Moffitt, T. E. (1993). Adolescence-limited and life-course-persistent antisocial behavior: A developmental taxonomy. Psychological Review, 100, 674-701. http://dx.doi.org/10.1037//0033-295x.100.4.674.

Molenaar, P. C., \& Campbell, C. G. (2009). The new person-specific paradigm in psychology. Current Directions in Psychological Science, 18, 112-117. http://dx. doi.org/10.1111/j.1467-8721.2009.01619.x.

Noom, M. J., Deković, M., \& Meeus, W. (2001). Conceptual analysis and measurement of adolescent autonomy. Journal of Youth and Adolescence, 30 , $577-595$.

Pearl, J. (2000). Causality: Models, reasoning, and inference. Cambridge, England: Cambridge University Press.

Pettit, G. S., Bates, J. E., Dodge, K. A., \& Meece, D. W. (1999). The impact of after-school peer contact on early adolescent externalizing problems is moderated by parental monitoring, perceived neighborhood safety, and prior adjustment. Child Development, 70, 768-778. http://dx.doi.org/10.1111/1467-8624. 00055.

Racz, S. J., \& McMahon, R. J. (2011). The relationship between parental knowledge and monitoring and child and adolescent conduct problems: A 10-year update. Clinical Child and Family Psychology Review, 14, 377-398. http://dx.doi.org/10.1007/s10567-011-0099-y.

Rankin, B. H., \& Quane, J. M. (2002). Social contexts and urban adolescent outcomes: The interrelated effects of neighborhoods, families, and peers on African-American youth. Social Problems, 49, 79-100. http://dx.doi.org/10.1525/sp.2002.49.1.79.

Rekker, R., Pardini, D., Keijsers, L., Branje, S., Loeber, R., \& Meeus, W. (2015). Moving in and out of poverty: The within-individual association between socioeconomic status and juvenile delinquency. PLoS One, 10,1-17. http://dx.doi.org/10.1371/journal.pone.0136461.

Roche, K. M., \& Leventhal, T. (2009). Beyond neighborhood poverty: Family management, neighborhood disorder, and adolescents' early sexual onset. Journal of Family Psychology, 23, 819-827. http://dx.doi.org/10.1037/a0016554.

Smetana, J. G. (2008). "It's 10 o'clock: Do you know where your children are?" Recent advances in understanding parental monitoring and adolescents' information management. Child Development Perspectives, 2, 19-25. http://dx.doi.org/10.1111/j.1750-8606.2008.00036.x.

Soenens, B., \& Vansteenkiste, M. (2010). A theoretical upgrade of the concept of parental psychological control: Proposing new insights on the basis of selfdetermination theory. Developmental Review, 30, 74-99. http://dx.doi.org/10.1016/j.dr.2009.11.001.

Soenens, B., Vansteenkiste, M., Luyckx, K., \& Goossens, L. (2006). Parenting and adolescent problem behavior: An integrated model with adolescent selfdisclosure and perceived parental knowledge as intervening variables. Developmental Psychology, 42, 305-318. http://dx.doi.org/10.1037/0012-1649. 42.2.305.

Stattin, H., \& Kerr, M. (2000). Parental monitoring: A reinterpretation. Child Development, 71, 1072-1085. http://dx.doi.org/10.1111/1467-8624.00210.

Steinberg, L., Mounts, N. S., Lamborn, S. D., \& Dornbusch, S. M. (1991). Authoritative parenting and adolescent adjustment across varied ecological niches. Journal of Research on Adolescence, 1, 19-36.

Tilton-Weaver, L. C., Burk, W. J., Kerr, M., \& Stattin, H. (2013). Can parental monitoring and peer management reduce the selection or influence of delinquent peers? Testing the question using a dynamic social network approach. Developmental Psychology, 49, 2057-2070. http://dx.doi.org/10.1037/a0031854.

Vieno, A., Nation, M., Pastore, M., \& Santinello, M. (2009). Parenting and antisocial behavior: A model of the relationship between adolescent self-disclosure, parental closeness, parental control, and adolescent antisocial behavior. Developmental Psychology, 45, 1509-1519. http://dx.doi.org/10.1037/a0016929.

Voelkle, M. C., Brose, A., Schmiedek, F., \& Lindenberger, U. (2014). Toward a unified framework for the study of between-person and within-person Structures: Building a bridge between two research paradigms. Multivariate Behavioral Research, 49, 193-213. http://dx.doi.org/10.1080/00273171. 2014.889593.

Willoughby, T., \& Hamza, C. A. (2011). A longitudinal examination of the bidirectional associations among perceived parenting behaviors, adolescent disclosure and problem behavior across the high school years. Journal of Youth and Adolescence, 40, 463-478. http://dx.doi.org/10.1007/s10964-0109567-9. 